\title{
Effect of Low-Cost Policy Measures to Promote Public Transport Use: A Case Study of Oyama City, Japan
}

\author{
Tomohide Azami $^{1, *}$, Kento Nakagawa ${ }^{2}$ (D) and Ayako Taniguchi ${ }^{2}$ (D) \\ 1 Urban Development Department, Oyama City, Chuohcho 1-1-1, Oyama 323 8686, Japan \\ 2 Department of Risk Engineering, University of Tsukuba, Ten-noh dai 1-1-1, Tsukuba 305 8573, Japan; \\ s2120544@s.tsukuba.ac.jp (K.N.); taniguchi@risk.tsukuba.ac.jp (A.T.) \\ * Correspondence: other.me.tomo@gmail.com
}

Citation: Azami, T.; Nakagawa, K. Taniguchi, A. Effect of Low-Cost Policy Measures to Promote Public Transport Use: A Case Study of Oyama City, Japan. Sustainability 2021, 13, 6160. https://doi.org/ $10.3390 /$ su13116160

Academic Editor: Antonio Comi

Received: 29 April 2021

Accepted: 27 May 2021

Published: 30 May 2021

Publisher's Note: MDPI stays neutral with regard to jurisdictional claims in published maps and institutional affiliations.

Copyright: (c) 2021 by the authors. Licensee MDPI, Basel, Switzerland. This article is an open access article distributed under the terms and conditions of the Creative Commons Attribution (CC BY) license (https:/ / creativecommons.org/licenses/by/ $4.0 /)$.

\begin{abstract}
Breaking away from the dependence on cars, increasing the number of public transport users, and securing operational revenues have been posing a problem for many cities worldwide. As a low-cost policy measure to address this problem, Oyama City (with a population of approximately 167,000 ) in Japan, conducted a social experiment involving a significant fare reduction (selling passes at Max $70 \%$ discount) and a public information campaign (simplified mobility management) for all citizens. This study analysed this policy from two perspectives, namely the change in the attitudes and behaviours of the people, and the maintenance of the financial stability of bus management. The analysis confirmed that the number of pass holders increased by a factor of 2.6, number of pass holders using the bus increased by a factor of 1.16, total number of annual bus users increased by a factor of 1.1, and revenue from bus services was maintained. In addition, public information campaigns increased awareness regarding the passes and the number of citizens who ware attached emotionally to the bus and city. These results suggest that the combination of a significant fare reduction and an appropriate public information campaign may increase bus ridership, without reducing operational revenues.
\end{abstract}

Keywords: public transport; bus; fare reduction; mobility management; communication campaign

\section{Introduction}

Breaking away from the dependence on cars, increasing the number of public transport users, and securing operational revenues have been posing a problem for many cities worldwide. This is particularly the case in many of Japan's smaller regional cities, where the increase in the number of private cars, aging of the population, and a decline in the number of children have led to a decline in the number of people using public transport, and a deterioration in the management of transport operators, thereby leading to a series of reductions and withdrawals of rail and bus services [1]. The search for low-cost solutions to this problem is an ongoing challenge for transport operators and public organisations.

Some cities and regions have implemented policy measures to structurally change the transport environment and soft policy measures, such as information and communication, have been introduced in an effort to solve this problem, with the aim of reducing the use of private cars and increasing the use of public transport.

Examples of policy measures to change the transport environment include public transport developments such as light rail transit (LRT) [2], road pricing [3], and fare reductions for public transport [4-8]. Several studies have shown the effects of fare reduction and free public transport, not only in terms of increasing the number of public transport users $[4,5]$ and encouraging the shift from private cars to public transport [6], but also in terms of increasing the amount of walking [7] and the frequency of visits to the city centre [7].

Policy measures that address the psychological aspects of people's behaviour include information campaigns aimed at changing travel behaviours from the usage of cars to the 
use of sustainable modes of transport, through the provision of specific information about public transport, travel education, word-of-mouth recommendations, and other means of communication: mobility management (MM) [8,9]. MM aims to change travel behaviours from car use to sustainable transportation (public transportation and active transport such as bicycles) by using communication measures such as providing specific information about public transport, travel education, and word-of-mouth recommendations [8,9]. The term MM will be used according to these definitions in this study, while MM is often referred to as a "Travel Plan" in the UK [10] and "Voluntary Travel behaviour Change" in Australia [11]. Based on research in social and environmental psychology, research on MM has been accumulating since the mid-1990s, and such research has contributed to the identification and development of effective methods to promote a modal shift [12]. In addition, factors that influence mobility choices, such as travel time and family structure, have also been studied [13-15]. MM practices have been reported not only in developed countries but also in developing countries. In Metro Manila, Philippines, a ride-sharing application for college students was developed to promote behaviour change [16,17]. In Japan, typical MM practices include personal conversations, workshops, educational activities in schools, and travel feedback programs (TFPs). These are used to solve the social problems caused by excessive car use [18]. In an MM program in Yamato City, Kanagawa Prefecture, participants were provided with pedometers in addition to leaflets and town guides to reduce car use and increase physical activity [19].

However, these policy measures to change the transport environment and psychological aspects (especially infrastructure construction) are not always politically feasible, as they are often very costly and difficult to implement for financially challenged municipalities.

The following is an example of the cost of policy measures. In terms of policy measures to change the transport environment, LRT construction was conducted in many cities worldwide, including France and Germany, at a cost of 2-4 billion yen/km [20]. In France, Versement Transport was introduced to finance construction [21] and was used to finance public transport services, with discounts for different age groups [22]. For example, in the United States, universities contracted with public transport companies to allow university students to use public transport for free. This appeared to increase the number of public transport users, reduce demand for university parking spaces, increase student attendance at school, reduce student commuting costs, and reduce the per capita transport costs of public transport $[23,24]$. As an example of discounted public transport in Japan, the operator of a tramway in Sakai City received a total of 5 billion yen in public support to reduce fares for 10 years (33\% reduction in fares and a 13\% increase in passengers) [5].

There are several cities that have implemented MM throughout their metropolitan areas, including London, UK, and Perth and Adelaide in Australia. Kyoto is a prime example in Japan. TFPs are a typical method of MM. TFPs are measures that expect spontaneous changes in transport behaviour through multiple individual interactions, including communication questionnaires and feedback based on questionnaires to the target audience $[8,11]$. Therefore, it is extremely expensive to implement in an entire metropolitan area. In Perth, Australia, approximately 640,000 people were targeted over a 10-year period at a cost of about 3 billion yen (about 10,000 yen/household, about 5000 yen/person) [25]. The Japanese city of Kyoto has a public budget of 33.5 million yen (about 1675 yen/person) for approximately 20,000 people [26].

Thus, a low-cost solution to the problem of promoting public transport use has not yet been established and requires some financial resources. However, while many studies have focused on the effects of public transport policies in increasing the number of passengers and promoting modal shift, few have studied the costs of these policies. In particular, one study [27] points out the high cost of these policies, but to the best of the authors' knowledge, there is no study that refers to the impact of public transport systems on the management and balance of payments. In addition, in Japan, there is no specific financial system for public transport policies, and the possibility of implementing these policies depends on the independent general funds of each municipality. Hence, cities 
that implement policies on a regional basis are generally more populous and have larger budgets for their own general funds. In smaller regional cities, both transport companies and public organisations are unable to implement policies on a wide scale, public transport remains inconvenient, and the region relies on private cars for mobility. The situation in Europe and the United States differs from that in Japan, as public organisations often operate public transport. However, promoting transport use should be encouraged to ensure financial stability of public organisations, considering the management and income of public transport.

This study analyses a low-cost solution implemented in Oyama City (population about $167,000)$, a small regional city in Japan with a similar problem to other smaller regions outside of Japan. It had two aims: to people's attitudes and behaviours but maintain the financial stability of bus management. This study is novel in the fact that it refers to the impact on the management and income of the public transport system. The low-cost solution here means a solution with low financial expenditure such as low implementation costs and no decreases in revenue for Oyama City, which is both a transport operator and a public organization.

Oyama City conducted a social experiment in which bus fares were significantly reduced (passes were sold at a discount of 50\% and 70\%) for one year starting in September 2019. Consequently, the experiment was completed without the use of additional public funds, the increase in revenue was confirmed, and the experiment was continued. In addition, a low-cost method of promoting bus usage was developed using MM knowledge, and a public information campaign for all citizens was launched in conjunction with the fare reduction, targeting approximately 53,000 households (about 125,000 people), and costing 18 million yen in public funds (about 340 yen/household, about 150 yen/person). This was less than a tenth of the per capita cost of MM. It is a novelty that the authors developed a low-cost method focusing on the cost of the policy and analysed its effectiveness.

This study aims to answer the following research questions, taking this initiative as an opportunity to organise and understand effective policies to promote public transport use.

1. How was the decision to design and implement a major fare reduction made?

2. What were the effects of a significant fare reduction?

3. What were the motivations, content, and implementation characteristics of the information campaign?

4. How did the low-cost approach to information provision and communication work?

Public transport fare reduction (discount) policies in Japan are largely welfare-based and are mostly aimed at students without a driver's license or at the elderly who are not confident about driving a private car. Reduced fares for commuters are often not supported as they are almost always paid for by their employer's commuting allowance.

However, as the commuting environment is likely to change in the future with the increase in the number of freelance workers and teleworkers who do not commute to the office, it would be useful for public transport policy in urban areas to examine whether reducing fares (discounts) for commuters would lead to a modal shift in public transport.

In addition, the low-cost and feasible policy measures reported in this study would encourage people in small cities who are dependent on private cars and who have not expressed interest in public transport, to reconsider its importance. It is hoped that this would lead to a debate on improving and promoting the use of public transport in cities, leading to more effective policy implementation and budgetary focus.

\section{Materials and Methods}

\subsection{About Oyama City}

Oyama city is located about $60 \mathrm{~km}$ north of Tokyo and has a population of about 167,000 (as of April 2021), making it the second most populous city in Tochigi Prefecture in Japan. From Oyama Station in the city centre, a rail service is provided by the Shinkansen and Tohoku Main Line (to Tokyo) to the north and south, the Ryomo Line to the west, and the Mito Line to the east. Among regional cities of the same size in Japan, the convenience 
of railways is quite high. However, there are only three stations located in the city, and the railways are not used for intra-city travel; they are mostly used for travel to Tokyo. Therefore, public transport within the city is carried out by buses. Private bus companies generally operate bus routes in Japanese cities, but there are no private bus companies in Oyama. There are 14 city bus routes that radiate from the station. The city bus service level is as follows: the most convenient route has 15 round trips per day, between 6:30 and 21:20; the least convenient route has six round trips per day between 6:32 and 19:05. According to the latest person-trip survey conducted in 2018 relating to the major modes of transport, $8.0 \%$ used rail, $0.3 \%$ used buses, and $69.0 \%$ used private cars. The rate of bus usage is very low, approximately one-tenth of the usage in other local cities in Japan. The city's Comprehensive Urban Transport Plan (formulated in FY2019) sets the goal of tripling the number of bus users by 2040. Owing to the very low number of bus users, the cost of operating the bus service is greater than the amount of revenue generated by the service and Oyama city pays for the shortfall. (This expression is used because public transport in Japan is usually financially independent.) In FY2018, before the low-cost policy was implemented, the number of users was 713,403 per year, operational costs were $257,136,882$ yen, and operational revenue was $119,103,997$ yen. The city pays $54 \%$ of the operational cost, and 138,032,885 yen per year in public expenses. This is one of the lowest percentages for buses operated by a local city in Japan; the average for cities in Tochigi Prefecture, of which Oyama is a part, is 78\% (as of FY2018) [28]. This study analyses the Oyama city bus social experiment offering a significant fare reduction with a public information campaign for all citizens.

\subsection{Design and Implementation Process of the Fare Reduction Social Experiment}

This section describes the outline and study process of the social experiment offering a significant fare reduction for city buses. The period of the social experiment was one year, from October 2019 to September 2020 (the reasons will be explained in detail), and the fare reduction was characterised by the following two points.

1. One and three-month passes provided price discounts of $50 \%$ off the old pass and new half-year and one-year passes were established, with price discounts of $70 \%$ off the old pass (see Table 1).

2. The new pass could be used on all lines rather than a specific line.

The pricing of this new pass was considered with the following three goals:

1. Shift cash-paying bus users to pass users. (This was because of the queues that had formed due to the exchange of currency, etc.)

2. Attract new bus users.

3. Keep the operational revenue as low as possible.

The following information was used as a reference in determining the price of a new pass.

- Results from a questionnaire survey of residents along bus routes

The percentage of residents who used the bus almost every day was $1.4 \%$ (estimated to be about 437 people when expanded to the entire city), the percentage of those who used the bus 2-3 days a week was $1.7 \%$ (530 people), the percentage of those who used the bus 1 day a week was $2.8 \%$ ( 874 people), the percentage of those who used the bus $2-3$ days a month was $7.6 \%$ (2371 people), and the percentage of those who used the bus 1 day a month was $6.1 \%$ (1903 people). The number of heavy users of the bus was small, and $80.4 \%$ of the residents along the bus routes did not use the bus.

- Number of old pass holders

The number of pass holders before the social experiment was approximately 120 . This number was quite small compared to the estimated 437 residents who used the bus almost every day.

- Other transport 
Parking lots around the station could be rented for 5000 yen/month (10-min walk from the station) to 10,000 yen/month (3-min walk from the station), and bicycle parking for 1000 yen/month. The price of the old pass was 8400 yen/month (see Table 1). The price of the old pass was not competitive with the rental prices of parking lots and bicycle parking lots around the station.

Table 1. Price of pass.

\begin{tabular}{|c|c|c|c|c|c|}
\hline \multicolumn{2}{|c|}{ Types } & Valid Period & $\begin{array}{c}\text { All People Except for } \\
\text { the Two Columns on } \\
\text { the Right }\end{array}$ & $\begin{array}{l}\text { Commuting to School } \\
\text { (Junior High School, High } \\
\text { School, University, etc.) }\end{array}$ & $\begin{array}{c}\text { Elementary School } \\
\text { Students, } 65 \text { Years Old and } \\
\text { Over, Disabled Person }\end{array}$ \\
\hline \multirow{4}{*}{ new pass } & \multirow[b]{2}{*}{$50 \%$ off } & 1 month & 4200 yen (11 days) & 3600 yen (9 days) & 2100 yen (11 days) \\
\hline & & 3 months & 12,000 yen (10 days) & 10,000 yen (9 days) & 6000 yen (10 days) \\
\hline & \multirow{2}{*}{$70 \%$ off } & 6 months & 15,000 yen (7 days) & 13,000 yen (6 days) & 7500 yen (7 days) \\
\hline & & 12 months & 28,000 yen ( 6 days) & 25,000 yen ( 5 days) & 14,000 yen ( 6 days) \\
\hline \multirow{2}{*}{\multicolumn{2}{|c|}{ old pass }} & 1 month & 8400 yen (21 days) & 7200 yen (18 days) & 4200 yen (21 days) \\
\hline & & 3 months & 23,940 yen (20 days) & 20,520 yen (18 days) & 11,970 yen ( 21 days) \\
\hline \multicolumn{2}{|c|}{ (Reference) Fares } & 1 way & 200 yen & 200 yen & 100 yen \\
\hline
\end{tabular}

The number of days in parentheses is the number of days per month that would be profitable if you used one route per day for one round trip (paid one way twice).

Initially, during the study phase, there was a concern about the decrease in operational revenue, and there was an opinion that a $30 \%$ discount, which had a precedent in Japan, should be used. In response to this, there was an opinion that with a $30 \%$ discount, the effect of goal 1 would be limited and goal 2 would not be achieved because of the priority given to goal 3; to attract new users, it was necessary to make the price feasible for the residents to easily pay, such as a $50 \%$ or $70 \%$ discount.

The number of pass holders before the social experiment was approximately 120 . The percentage of residents who used the bus almost every day was as low as $1.4 \%$ (437 people). In contrast, city authorities hypothesised that if residents who used the bus at least 2-3 days a month (estimated number: 4212) purchased the new pass, the increase in revenue from new bus users would outweigh the decrease in revenue from the fare reduction. By adding value to the new pass, such as making it available for use on all lines, it would be possible to achieve this goal.

The results of the trial calculations are presented below. If only 120 people purchased new passes, the revenue would be reduced by about 700,000 yen/month; if only 437 people purchased new passes, the revenue would be reduced by about $21,000,000$ yen $/ \mathrm{month}$, and if 4212 people purchased new passes, the revenue would increase by about $18,000,000$ yen/month

The above results were calculated simply by multiplying the number of people in each group by the difference between the average fare paid and the lowest price of the new pass. The average fare paid was calculated by multiplying the frequency of use and the average fare paid per one-way trip, which is 167 yen. The 167 yen was calculated by dividing the FY2018 revenue of $119,103,997$ yen by the number of users $(713,403)$. The average fare paid is set at $8400 \mathrm{yen} / \mathrm{month}$ (price of old pass) for the group of 120 people, $7300 \mathrm{yen} / \mathrm{month}$ for the group of 437 people, 1980 yen/month for the group of 4212 people, and the price of the new pass is set at $2400 \mathrm{yen} / \mathrm{month}$.

After the above discussion, city authorities decided to sell the new pass with the prices listed in Table 1. This meant that although there was no certainty that the revenue would not decrease, the decision to reduce the price was made because it was assumed that an increase in the number of bus trips and new bus users was necessary to make the transport environment in Oyama more sustainable, and the authorities were determined not to lose revenue through the public information campaign (see below).

When city authorities proposed the fare reduction, the mayor and the Regional Public Transport Council (the body that regulates bus fares) expressed concern about the increased burden on public funding. In response to this, city authorities presented the data and 
explained that the revenue would not necessarily decrease and that even if it did, the amount would be small. This was because the number of bus users and old pass holders who paid a large amount of money was small. The availability of data to explain the situation accurately was a big advantage.

In addition, the following two points were proposed to persuade them:

- The fare reduction should be for a period of one year. A decision on whether to continue the fare reduction will be made depending on the level of operational revenue.

- Sales of the new pass will be limited to My Number card holders. The mayor had made it a political goal to increase the percentage of residents who obtained a My Number card.

After lowering the conditions and making a proposal that met his political goals, the mayor gave his approval for the fare reduction. The proposal was subsequently approved by the Regional Public Transport Council, and the fare reduction started in October 2019. In addition, an increase in revenue was achieved after the start of the social experiment. For this reason, it was decided to extend the period by one year, until September 2021, and to continue the fare reduction.

\subsection{Motivation, Contents, and Implementation of the Public Information Campaign}

The aim of the public information campaign was to provide all citizens with information about the bus, including the new pass, and to reach out to them psychologically to increase their opportunities to use the bus.

To achieve this objective, three lifestyle information tabloid newsletters (LITNs) for the buses were created (Nos. 1-3). Each of these was distributed to all households in Oyama City. The LITNs were developed as a tool for the campaign to achieve the following features: to provide information in a news format; to enclose route maps and timetables as appendices; and to reach out to readers psychologically through columns and feature articles.

$\mathrm{MM}$ in this study was not an experiment, but a transport policy. In order to encourage people to change their attitudes and behaviours, the quality of the MM communication tools is very important. In order to guarantee this quality, a review committee was formed to create the LITNs consisting of city authorities, special advisors, creative directors, and designers. The committee used the KJ method to define the core brand message and thus, "Living in Oyama, Bus in your life." was created. Efforts were made to ensure that this core brand message was communicated to the public through the LITNs. The committee spent approximately $30 \mathrm{~h}$ discussing the plan, design, and articles for the conception of the LITNs. A sample of the articles is shown in Figure 1, and the contents of the LITNs in Table 2. The articles in the LITNs had the following characteristics, based on the knowledge of MM, to reach people psychologically, and to encourage them to change their spontaneous travel behaviour. A part of it is shown in Figures 2-4.
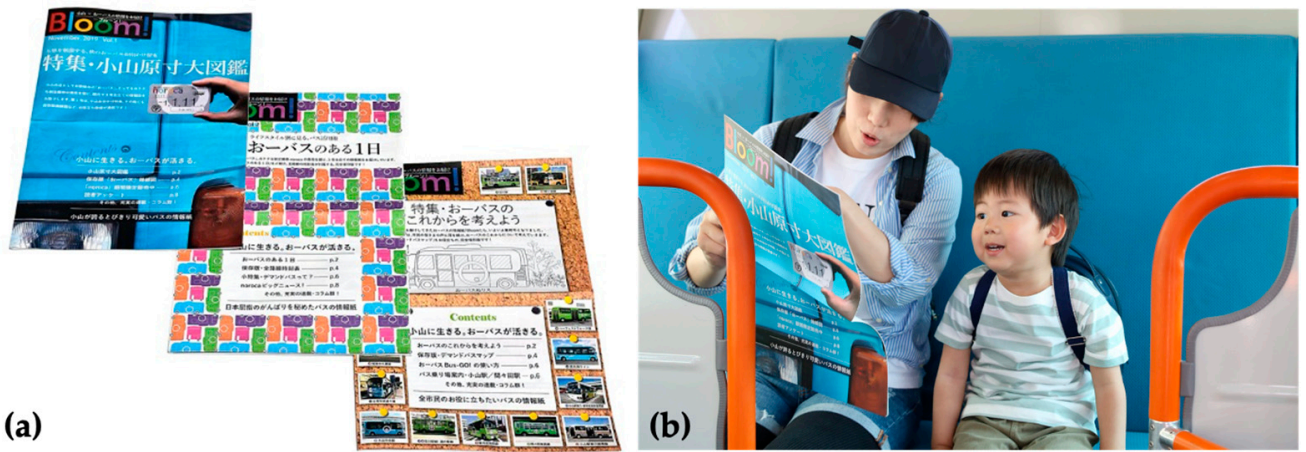

Figure 1. Example of the LITNs; (a) These are the covers of LITNs No. 1 (left-most) to No. 3 (right-most) (The words in the picture serve as a table of contents. Specifically, the contents listed in (2) to (8) of Table 2 are written in Japanese.); (b) Reading LITN No. 1. 
Table 2. Contents of the LITNs.

\begin{tabular}{|c|c|c|c|}
\hline & No. 1 & No. 2 & No. 3 \\
\hline (1) Cover & $\begin{array}{l}\text { Full-size photo of a bus and the } \\
\text { new pass }\end{array}$ & Pictogram of a bus & $\begin{array}{l}\text { Bus coloring book and vehicle } \\
\text { illustration book }\end{array}$ \\
\hline (2) Special feature & $\begin{array}{l}\text { Oyama full-size picture: } \\
\text { Introduction to places to visit by } \\
\text { bus in the city }\end{array}$ & $\begin{array}{l}\text { A day with a bus: Information about a } \\
\text { day on the bus and the places visited } \\
\text { by five representative people }\end{array}$ & $\begin{array}{c}\text { Let's think about the future of the } \\
\text { bus: opinions and answers from } \\
\text { citizens }\end{array}$ \\
\hline (3) Appendix & Bus route map & Bus timetable & Demand Bus map \\
\hline (4) Service Introduction & $\begin{array}{l}\text { Information about the new pass } \\
\text { and how to ride the bus }\end{array}$ & How to ride the Demand Bus & $\begin{array}{c}\text { How to use the bus location } \\
\text { system }\end{array}$ \\
\hline (5) People behind Bus & & Introduction to the bus operators & \\
\hline (6) The History of Bus & No more buses from Oyama! & Private buses, complete withdrawal. & $\begin{array}{l}\text { Let's think about the future of } \\
\text { buses }\end{array}$ \\
\hline (7) Serial Columns & Clothes and vehicles & How to make a bus survive & Is it true that cars are cheap? \\
\hline $\begin{array}{l}\text { (8) The secrets of the bus } \\
\text { (for children) }\end{array}$ & Bus body measurements & A day in the life of a bus driver! & The mileage of the bus is amazing! \\
\hline
\end{tabular}

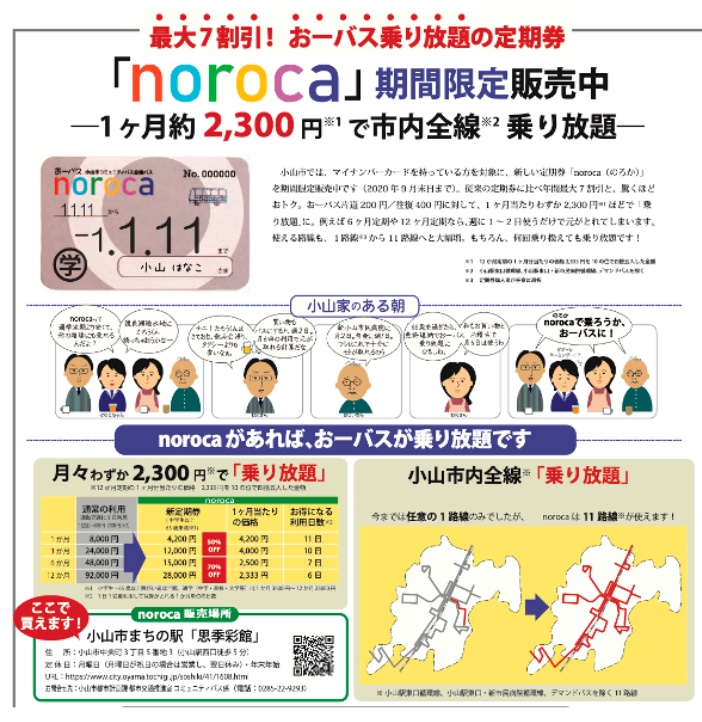

(a)

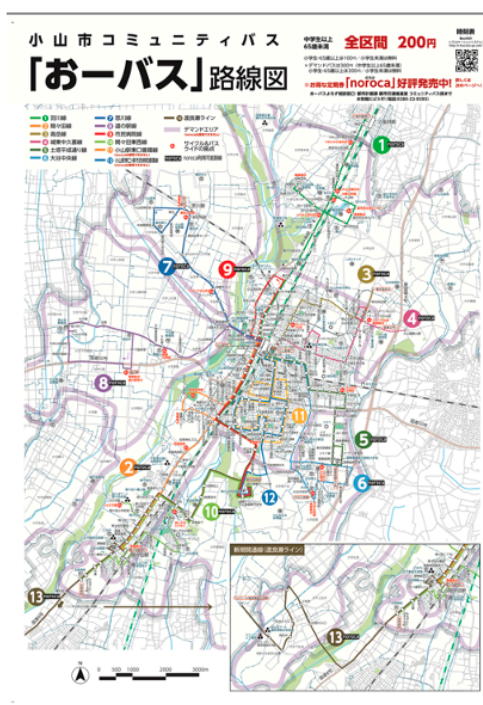

(b)

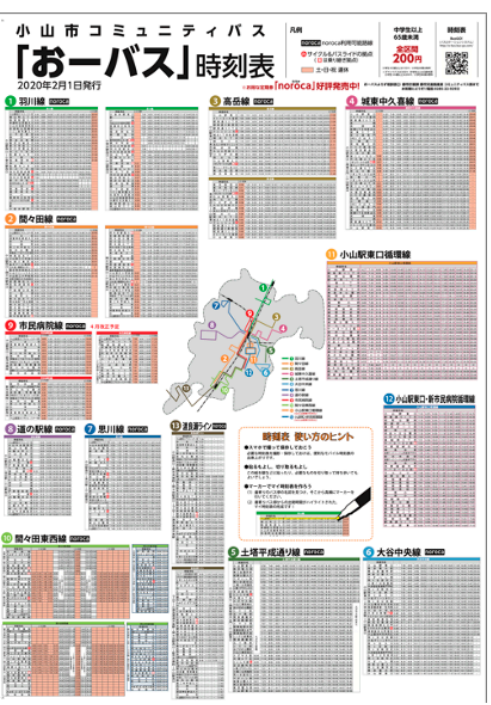

(c)

Figure 2. Example of the LITNs; (a) Information on the new pass; (b) Bus route map; (c) Bus timetable.

\section{- Information}

Information on the new pass, bus route maps, and timetables for all routes: The provision of information is the basis of MM (See Figure 2).

- Individual communication

Information about a day on the bus and the places visited by five representative people. The aim was to give citizens the feeling that they were being addressed individually, that they too could move like the person in the figure (see Figure 3). In addition, by applying the technique of the action plan method of MM [29], a column was prepared in which citizens could create their own "action plan for a day using the bus" and send it to the secretariat (see Figure 3, rightmost column).

- Interactive communication

In response to the questionnaires in LITNs No. 1 and 2, we received comments such as "I would like to see an increase in the number of bus services", "There are other ways to 
use the bus", and "My image of the bus has changed after reading this tabloid" and these opinions and answers were published in LITN No. 3 (see Figure 4).

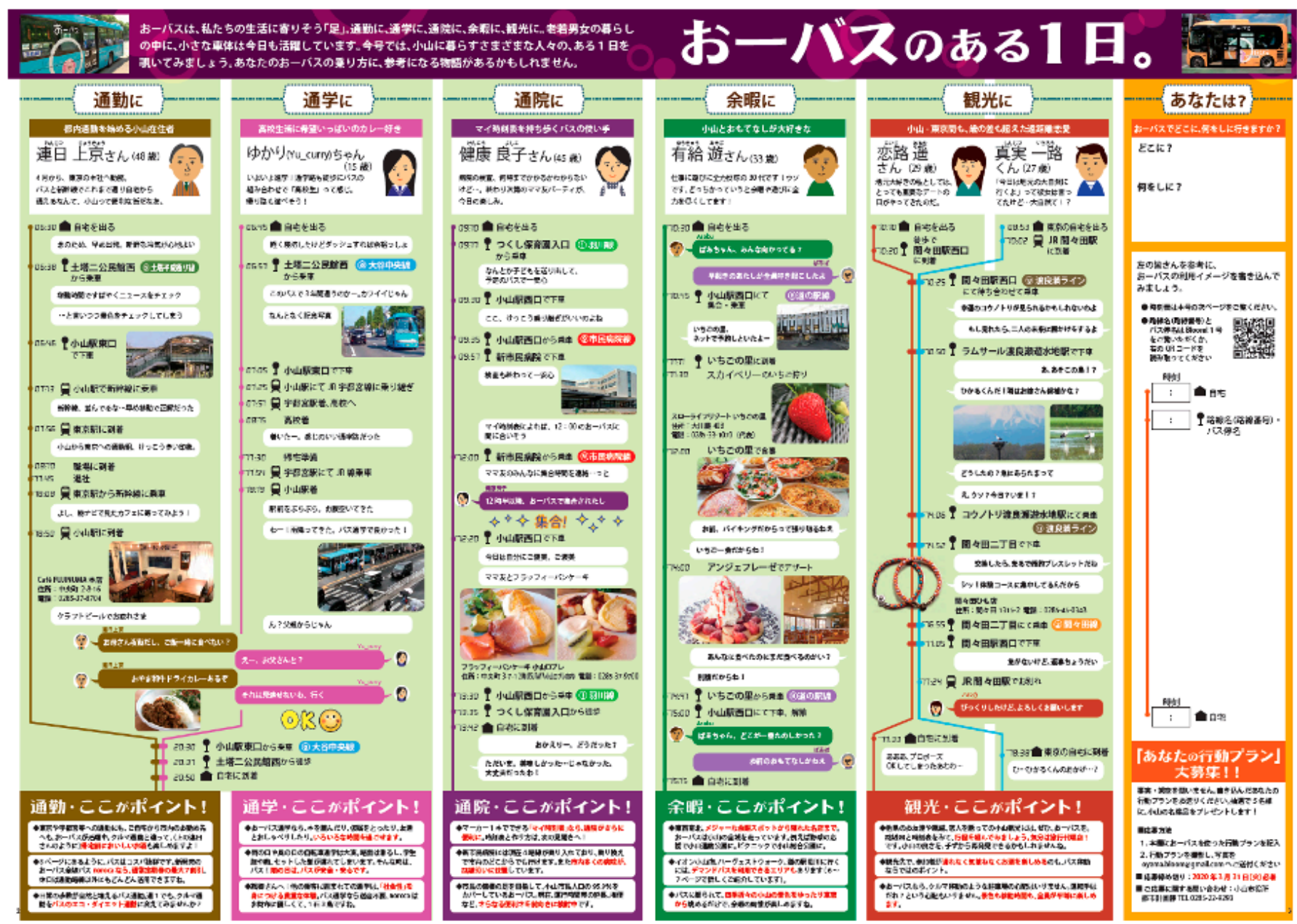

Figure 3. Example of the LITNs: A day with a bus; Information about a day on the bus; and the places visited by five representative people.

This showed the attitude that "City authorities are receptive and responsive to the opinions of its users and readers". This was based on the technique of the TFP $[8,11]$, a communication program that involved repeated feedback, such as a survey of an individual's traffic behaviour and the presentation of a medical report based on the results.

In this way, LITNs articles could provide a pseudo-individual communication experience for the majority of citizens by featuring representative people and opinions (which everyone has and wants to have answered) and could appeal to the emotional side.

There were other articles about the bus that even citizens who were not interested in the bus could enjoy reading. For example, articles on the role of buses in helping people discover new attractions and enriching their lives in Oyama. By distributing the LITNs in one direction to the citizens, the operational cost was reduced by omitting individual communication with each citizen. The distribution schedule was November 2019 for No. 1, February 2020 for No. 2, and May 2020 for No. 3. Each had a print run of 60,000 copies. Of these, 53,000 (all households belonging to the local community association) were distributed on the city hall's monthly PR magazine delivery network. Therefore, there was no cost for the distribution.

The characteristics of this low-cost method of public information campaigning (simplified MM) could be summarised as follows: 
- The omission of time-consuming and costly one-to-one communication and the use of representative people and opinions as an alternative to provide quasi-individual communication.

- Distribution using existing networks at no additional cost.

Therefore, the cost of the campaign was 18,000,000 yen for the planning, production, and printing of LITNs. Since LITNs were distributed to about 125,000 people, the per capita cost was 150 yen. This is less than a tenth of the per capita cost of about 5000 yen in Perth, Australia [25], and 1675 yen in Kyoto, Japan [26].

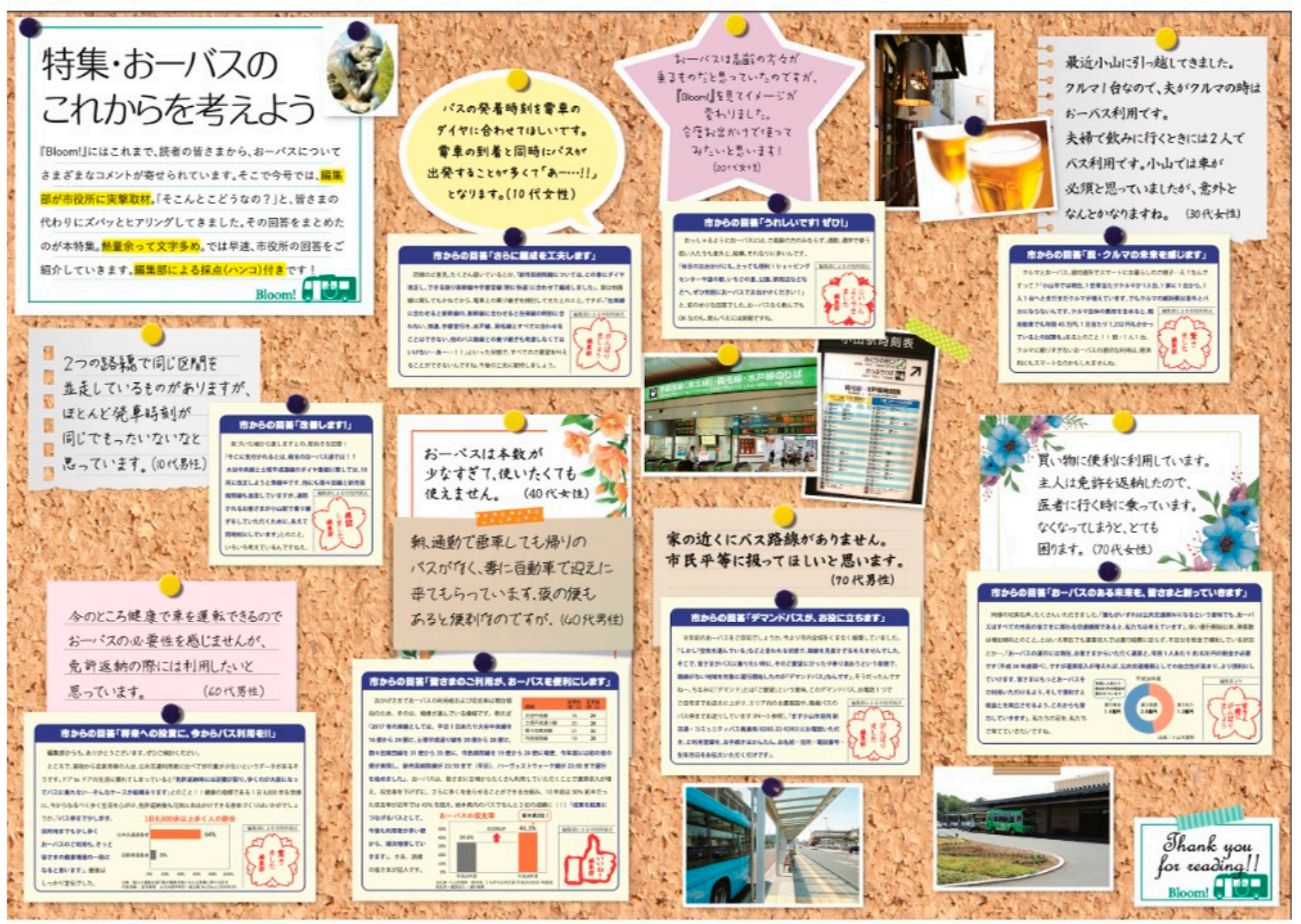

Figure 4. Example of the LITNs; Let's think about the future of the bus: opinions and answers from citizens.

\subsection{Data Used in the Analysis}

The following data on bus operation were provided by Oyama City, the operator of the bus service.

Data in months

- Number of passes sold, revenue, and age of purchasers (April 2018 to March 2021)

- Number of bus users (April 2019-March 2021)

- Operational revenue (April 2019-March 2021)

Data in years

- $\quad$ Number of bus users (FY2008-FY2020)

- Operational cost and revenue (FY2008-FY2020)

Two types of questionnaires were distributed. 
The first was a survey of new pass holders. This was carried out in April 2020, six months after the start of the new pass. The fare reduction was scheduled to end in September 2020 so the survey was conducted at this time to obtain information for further consideration. The survey covered 184 holders of the new pass (as of the 3rd of April 2020). The questionnaire responses and indices are listed in Table 3. The survey was conducted by post, and 127 respondents (69\% response rate) participated. The questionnaire results were used to analyse changes in transport behaviours and awareness of new pass holders.

Table 3. Questionnaire responses and indices (the new pass holders).

\begin{tabular}{lcc}
\hline \multicolumn{1}{c}{ Index } & Questions Used in Survey Calculation & Scale \\
\hline (1) Frequency of bus use (for September 2019) & How many times did you use the bus during September 2019? & Times $/$ month \\
(2) Frequency of bus use (for February 2020) & How many times did you use the bus during February 2020? & Times /month \\
(3) Frequency of bus use (for April 2020) & How many times did you use the bus during April 2020? & Times/month \\
(4) Possession of driving licence & Do you have a driving licence? & No/yes \\
(5) Possession of own car & Do you have your own car? & No/yes \\
(6) Free opinion column & & - \\
\hline
\end{tabular}

The second was a questionnaire survey for LITNs readers with a similar questionnaire attached to each of the three tabloids distributed. Readers responded by post or via the web. The questionnaire responses and indices are listed in Table 4 . The number of responses was 183 for No. 1, 101 for No. 2, and 121 for No. 3 (not a panel survey). The questionnaire results were used to analyse changes in the attitudes of LITNs readers.

Table 4. Questionnaire responses and indices (readers of the LITNs).

\begin{tabular}{|c|c|c|}
\hline Index & Questions Used in Survey Calculation & Scale \\
\hline (1) Awareness of the new pass (Only web survey) & Did you know that the new pass is on sale? & No/yes \\
\hline (2) Intention to purchase the new pass & Do you want to buy the new pass? & No/yes (five-point scale) \\
\hline (3) Favor to the bus & Do you like the bus? & No/yes (five-point scale) \\
\hline (4) Attachment to the city (1) & Do you feel attached to Oyama? & No/yes (five-point scale) \\
\hline (5) Attachment to the city (2) & $\begin{array}{l}\text { Do you think there are things in Oyama that } \\
\text { you would be sad to see disappear? }\end{array}$ & No/yes (five-point scale) \\
\hline (6) Free opinion column & - & - \\
\hline
\end{tabular}

\section{Results}

\subsection{Changes in the Number of Pass Holders and Age Structure}

As of 31 March 2021, 807 new passes were sold. The number of new pass holders continues to increase despite the COVID-19 disaster. Compared to the average number of old pass holders, which was about 118, the number of new pass holders was 308 as of March 2021, an increase of about 2.6 times (see Figure 5). Of the 301 people who had purchased the new pass as of November 2020 (this was the time point due to data limitations), 44 pass holders $(15 \%)$ were transferred from the old pass, while the remaining 257 (85\%) were new purchasers.

Following this, the characteristics of the sales of the new pass by period of validity were as follows: As of March 2021, the largest number of new passes were sold for 12 months (124 holders), followed by six months (91 holders), one month (18 holders), and three months (15 holders). The 12-month pass was not the most popular from the beginning. The highest number of 12-month passes was recorded in May 2020, seven months after the start of the study. Prior to this, the number of 1-month and 6-month passes was high, and the number of 12-month passes gradually increased. The reasons for this are discussed below. At the beginning of the introduction of the new pass, it was considered that many people bought a one-month pass as a trial because they were not sure of the extent of their usage of the bus, and several bought a six-month bus pass if they wanted to buy a pass with a higher discount rate. This was also the opinion expressed at the sales offices. 
The age structure of the 301 new pass holders (as of January 2021) was as follows: The age structure of the new pass holders was compared to the age structure of the bus users in the 2018 Parson trip survey (see Figure 6) to clarify their characteristics. The division of the age structure of the new pass holders was calculated to match the results of the Parson Trip survey. The age structure of the new holders included a higher proportion of school-going people aged 15-24 and working people aged 25-65, compared to the age structure of bus users in 2018. The generation that was able to obtain a driving license and was not worried about driving a car, also purchased the new pass. Of the 127 respondents to the questionnaire, $78(61 \%)$ held a driving license and $54(43 \%)$ had a private car (see Figure 7).

Figure 5. Number of pass holders by validity period.

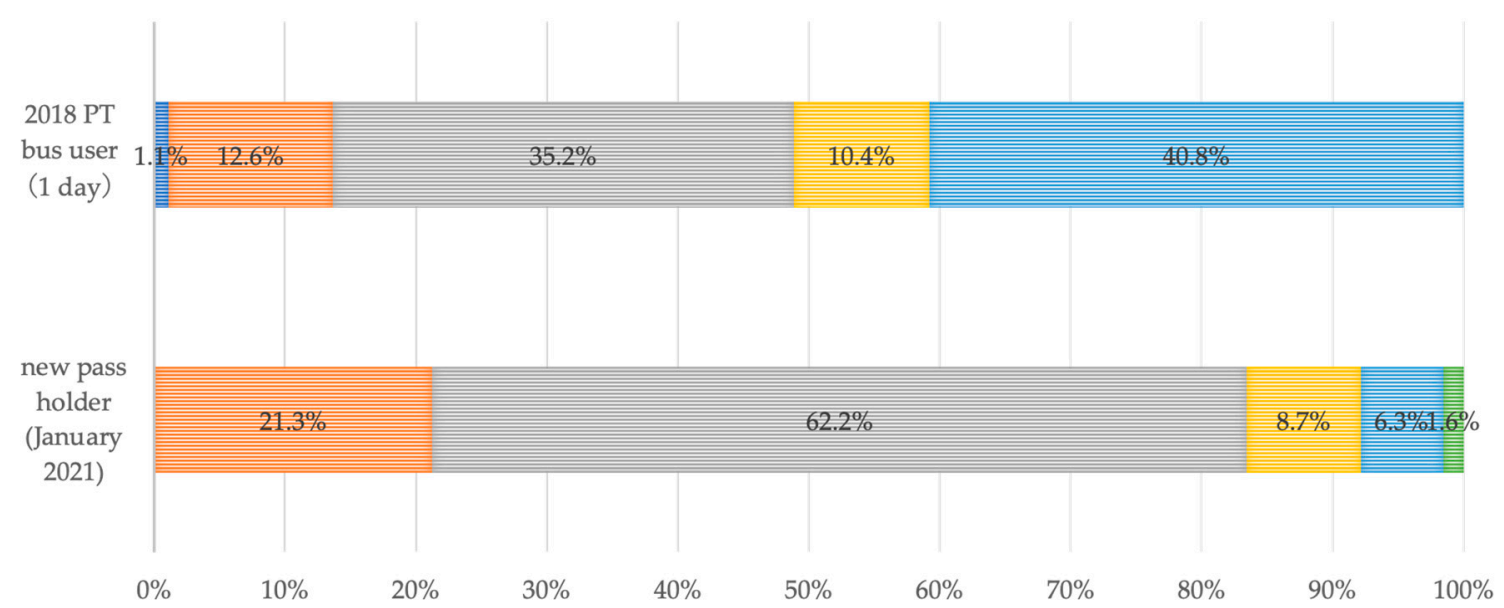

Figure 6. Age structure of the new pass holders (301 as of January 2021). 


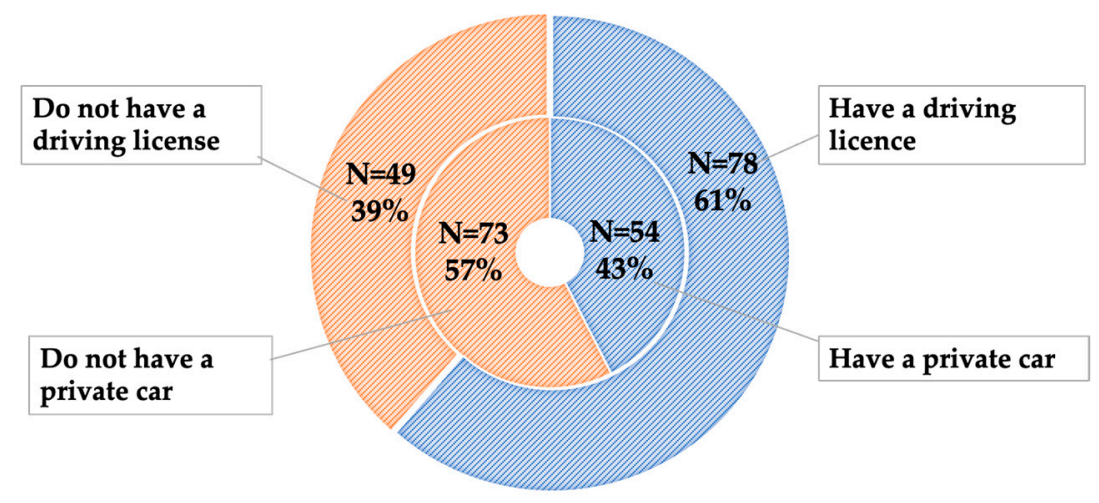

Figure 7. Possession of a driving licence and private cars by the new pass holders (a survey for the new pass holders $\mathrm{N}=127$ ).

\subsection{Changes in Users and Operational Revenue (Monthly)}

Figure 8 shows the number of bus users per month from April 2019 to March 2021. The number of bus users in 2020 dropped significantly due to COVID-19, declining to 27,768 passengers in May 2020 (45\% of the same month from the previous year) and recovering to 52,495 passengers in October 2020 ( $84 \%$ of the same month from the previous year). However, due to the declaration of a state of emergency, the number of visitors dropped to 39,239 (65\% of the same month from last year) in January 2021. In addition, as the comparison with the same month from the previous year in February 2020 turned negative $(-1.7 \%)$, the number of users started to decrease around the end of that month, due to the impact of COVID-19.

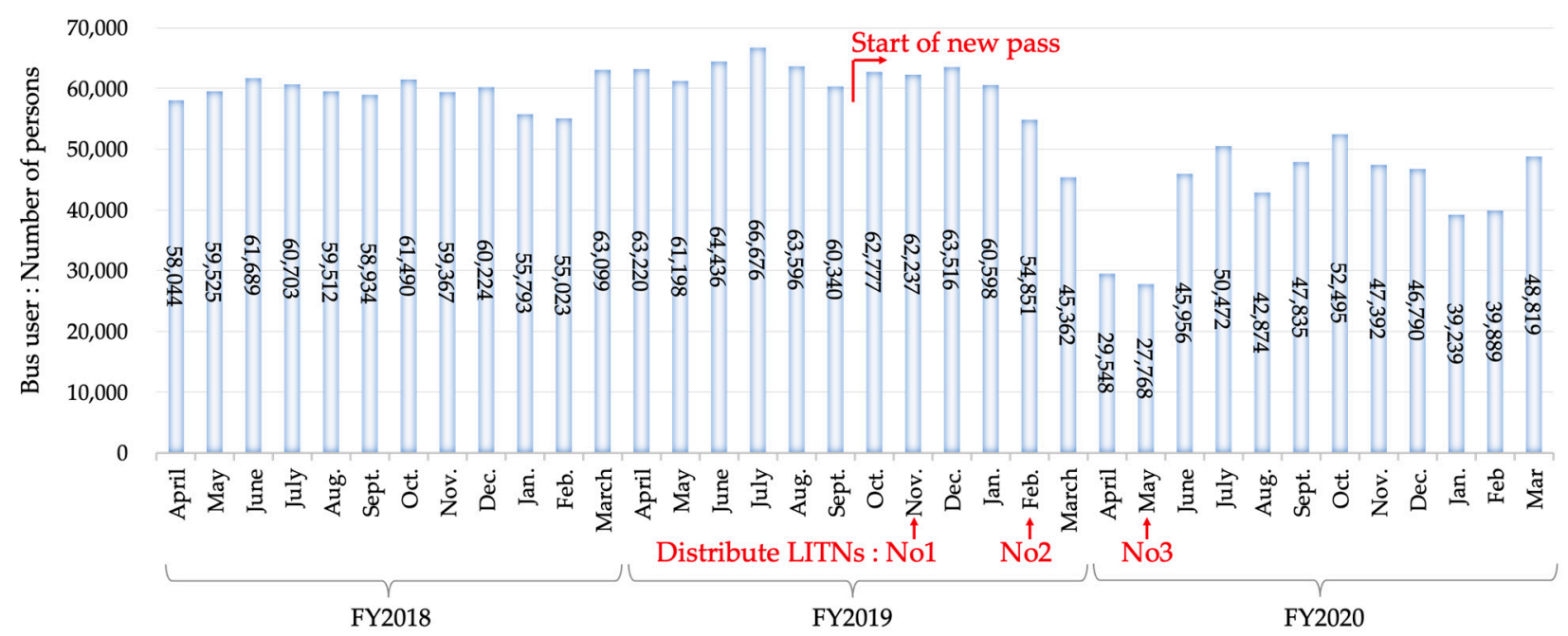

Figure 8. Changes in bus users (Data in months).

Figure 9 shows the monthly operational revenue from April 2019 to March 2021. The operational revenue was also affected by COVID-19, especially in April and March 2019. From October to December 2019, after the new pass was issued, there was no significant change in operational revenue, but the share of operational revenue accounted for, by the sales of the pass, was gradually increasing. Comparing this revenue with the previous year (2018), the total revenue from October to December 2018 was 29,031,184 yen, and the total revenue from October to December 2019 was 29,813,289 yen, with an increase of 782,105 yen. Additionally, revenue from the passes also increased by 831,820 yen (34.7\%) from 2,397,360 yen in October to December 2018 to 3,229,180 yen in October to December 2019. 


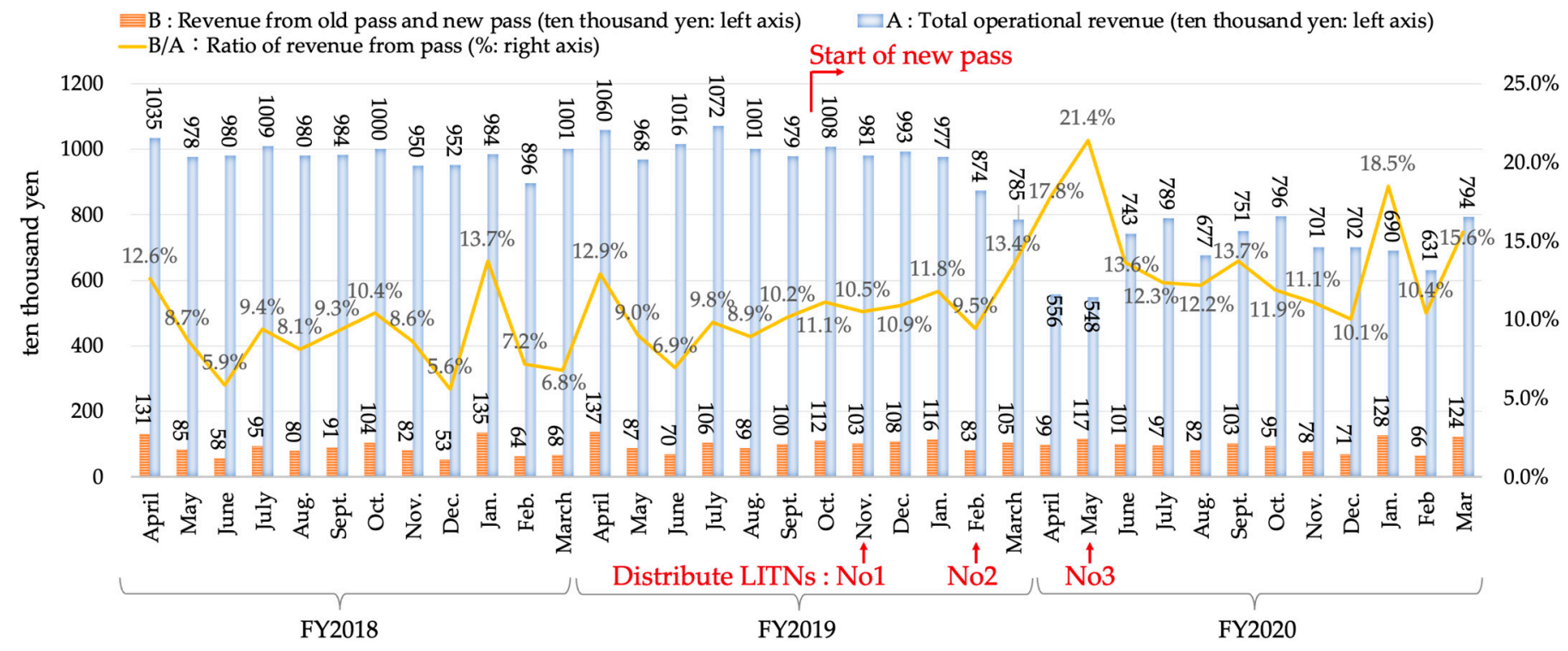

Figure 9. Changes in operational revenue (Data in months).

The situation under the influence of COVID-19 from February 2020 onwards is shown below. As mentioned above, the operational revenue decreased significantly due to the impact of COVID-19. However, the revenue from the sale of the new passes had not fallen as much as the revenue from the total operational revenue, although it had fluctuated. The share of revenue from the sale of the new pass in the operational revenue had increased since the start of COVID-19, up to $21.4 \%$. These results suggest that the new pass contributed to an increase in revenue and might raise the level of revenue under the influence of COVID-19.

\subsection{Changes in Users and Operational Revenue (Annual)}

Figure 10 shows changes in the annual number of bus users, and Figure 11 shows changes in the annual operational cost, operational revenue, and balance ratio.

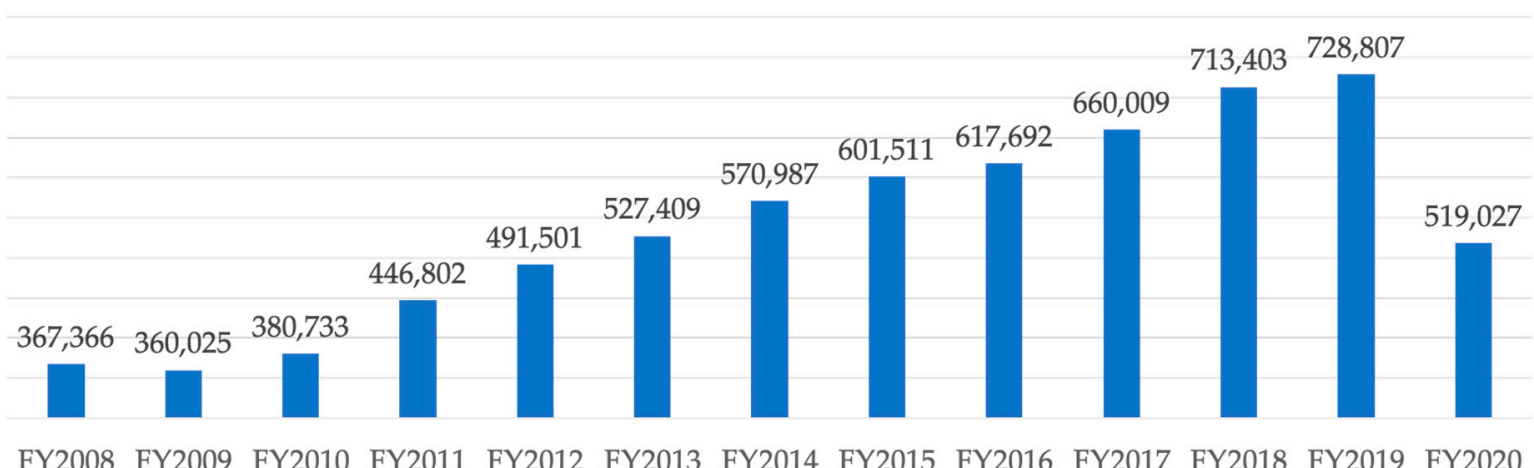

Figure 10. Changes in bus users (Data in years).

In FY2019, although the bus service was affected by COVID-19 in February and March 2020, it achieved an increase from 119,103,997 yen in revenue and 713,403 bus users in FY2018, before the introduction of the new pass, to 119,366,680 yen in revenue and 728,807 bus users in FY2019, after the introduction of the new pass, with an increase of 262,683 yen in revenue and 15,404 users.

If there had been no impact from COVID-19 and the same number of users as in the previous year, it was estimated that the number of users in March 2020 would have been around 18,000 (63,099 users (March 2019) minus 45,362 users (March 2020) equals 17,737). 
Furthermore, it is estimated that the revenue would have increased by 3,000,000 yen (i.e., the aforementioned 18,000 multiplied by the average fare paid per one way of 167 yen). However, 1001 ten thousand yen (revenue in March 2019) minus 785 ten thousand yen (revenue in March 2020) equals 216 ten thousand yen. This small amount is likely due to the impact of revenue from passes.

Although no changes were made to the bus service between FY2018 and FY2019 that would have increased operational costs, the costs increased, nonetheless, by approximately $8,000,000$ yen, due to vehicle repairs and other costs, resulting in a slight decrease in the revenue/income ratio (see Figure 11 ).

In FY2020 (preliminary figures), when the full impact of COVID-19 was felt, there was a significant decrease in revenue of $85,275,021$ yen $(71.4 \%$ of the previous year) and 519,027 bus users ( $71.2 \%$ of the previous year). The percentage decrease was approximately the same.

For reference, the author reviewed similarly sized cities to the Tochigi Prefecture to investigate the number of people who used the city bus in FY2020, compared to the previous year. The numbers were $65.6 \%$ in Ashikaga (population about 143,000 ), $66.2 \%$ in Tochigi (population about 154,000), and $64.4 \%$ in Sano (population about 115,000 ). Oyama City bus usage declined about 5 percent less than in the surrounding cities.

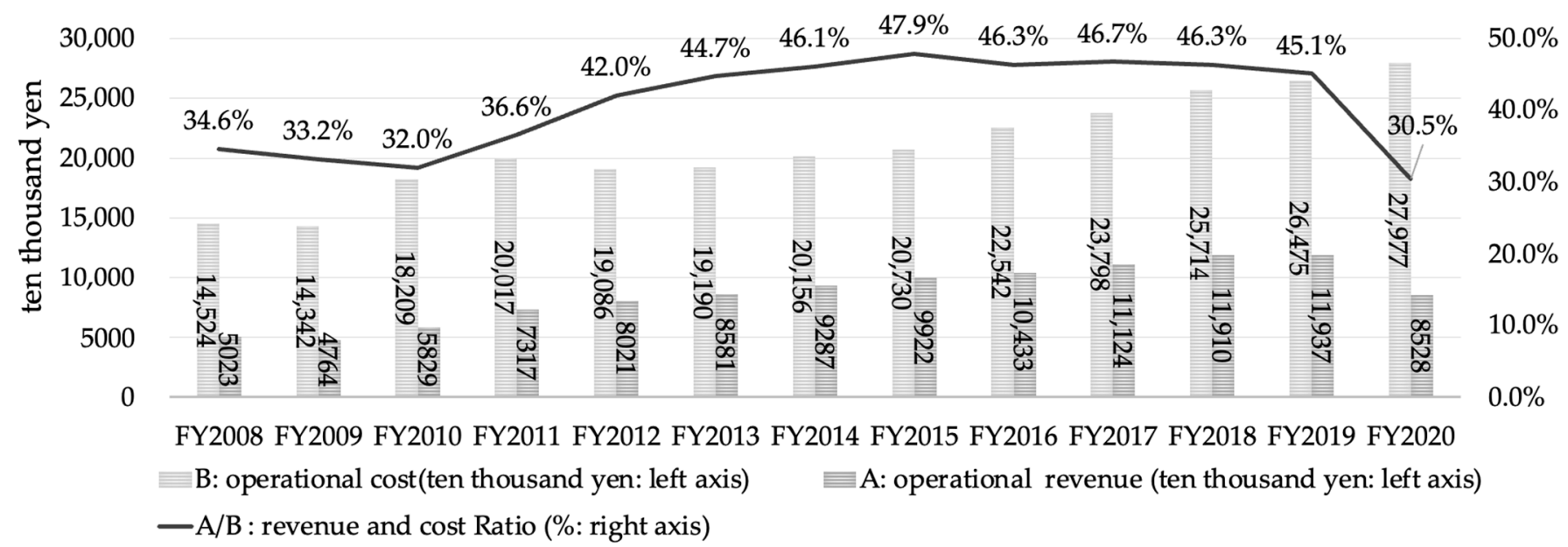

Figure 11. Changes in operational cost, revenue and balance ratio (Data in years).

\subsection{Changes in the Number of Times the Bus Was Used by New Pass Holders}

Based on the questionnaire responses from the new pass holders ( $n=127)$, the average number of times the bus was used per month is depicted at three time points (see the left-most of Figure 12). Owing to the t-test for the number of times the new pass holders used the bus between the three time points, the $t$-value (two-tailed) $=1.98$ indicating a significant difference. This indicated that the number of times the new pass holders used the bus was higher after the purchase than before the purchase (increased by 1.16 times), and that the number of times might have decreased due to the effect of COVID-19. It should be noted that the April 2020/February 2019 ratio of the actual number of users of city buses as a whole was $53 \%$, while the same ratio for new pass holders based on the questionnaire survey was $80 \%$. The reason for this difference could be explained by the fact that the new pass holders in April 2020 might be those who had to use the bus daily, even under the influence of COVID-19. However, about $70 \%$ of the 158 new pass holders as of April 2020 (108 people) purchased a new pass before February 2020 (before the impact of COVID-19). Therefore, the possession of the new pass might discourage people from refraining from using buses under the influence of COVID-19. 


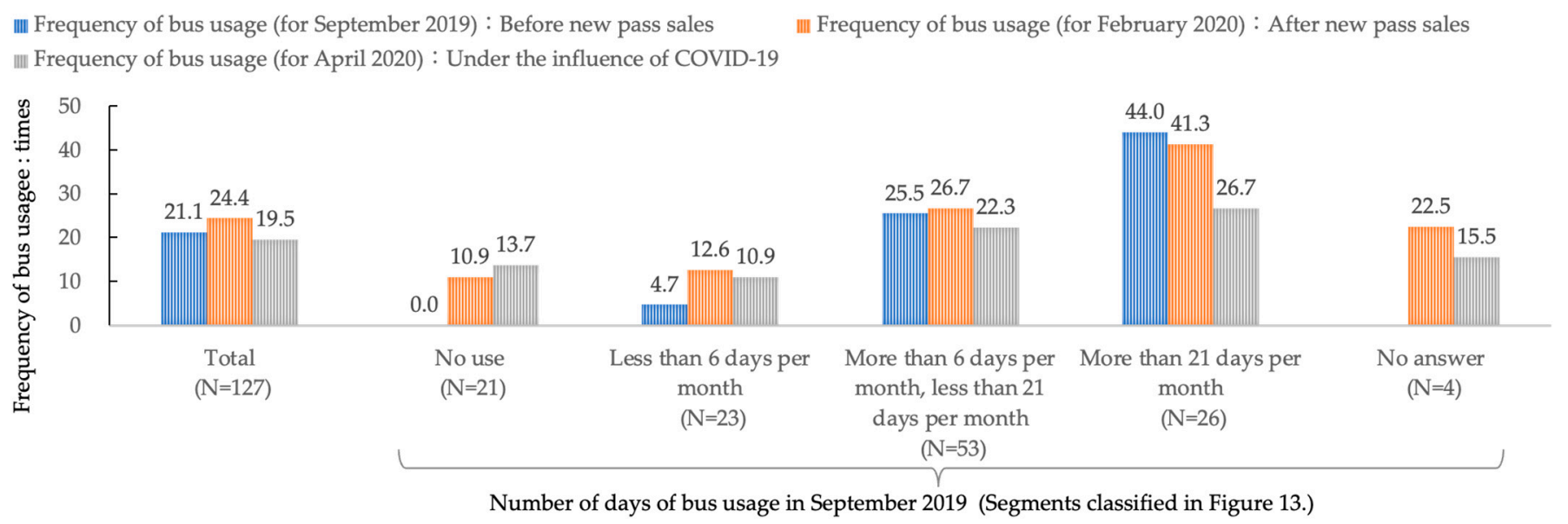

Figure 12. Frequency of bus usage: New pass holders $(n=127)$ using the bus per month (three time points).

Figure 13 shows the distribution of the number of days spent on the bus per month before the purchase of the new pass (September 2019) for 127 survey respondents.

The threshold of the graph is as follows.

Six days (more than 12 times per month and less than 21 times per month): the payment of the 12-month new pass was cheaper than the cash payment each time.

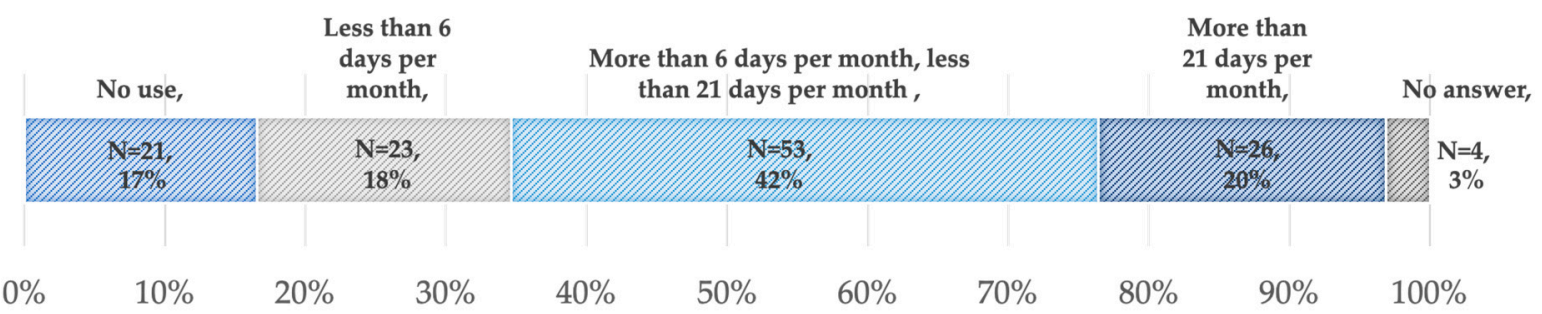

Figure 13. The distribution of the number of days spent on the bus per month before the purchase of the new pass (September 2019).

Twenty one days (more than 42 times per month): the payment for using the old pass was cheaper than the cash payment each time.

Before purchasing the new pass, $77 \%$ of the survey respondents used the bus for less than 21 days and were previously not heavy enough users of the bus to buy the old pass.

Next, the frequency of bus usage by the new pass holders was considered, using the segments classified in Figure 13 (see Figure 12). People who used the bus more than 6 days a month and those who used the bus for more than 21 days a month did not change the number of times they used the bus by purchasing the new pass. Conversely, those who never used the bus before and those who used the bus less than 6 days a month before, increased the number of times they used the bus (increased 2.68 times). These results showed that those who previously (September 2019) used the bus for more than 6 days a month did not increase their bus usage after purchasing the new pass. In contrast, those who previously used the bus for less than 6 days a month or not at all would use the bus for about 6 days (about 6 round trips: about 12 times) after purchasing the new pass.

In other words, the existence of the new pass suggested that citizens who had never used the bus could be converted into bus users.

\subsection{Impact of the Lifestyle Information Tabloid Newsletters (LITNs) on the Citizens}

The awareness of the new passes increased by $26.9 \%$ (from $19.3 \%$ to $46.2 \%$ ), from LITN No. 1 to No. 3 (see Figure 14, far right). 


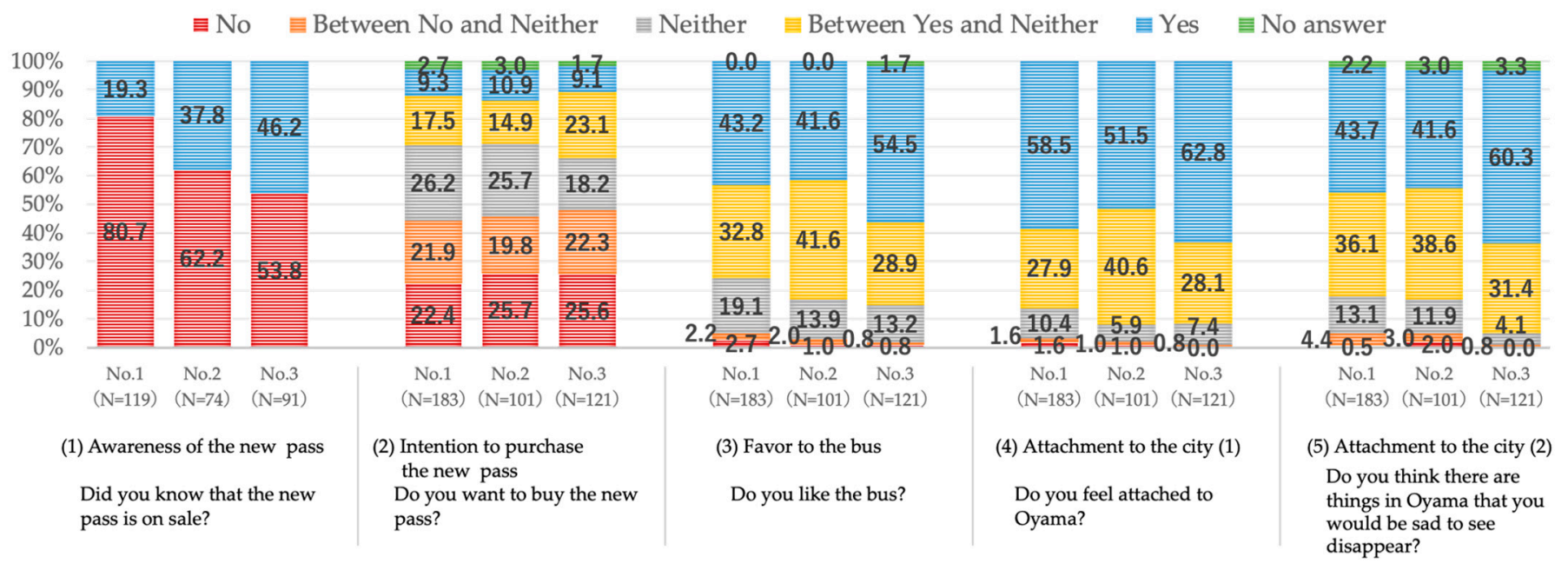

Figure 14. Results of questionnaire responses from readers of LITNs.

It was assumed that the awareness of the new pass had increased because of the articles about the new pass in each LITN.

Regarding the intention to purchase the new pass (see Figure 14, second from the right), there was no difference between No. 1 and No. 2, but the proportion of those who answered "Between Yes and Neither" increased by 8.2 points in No. 3.

The proportion of respondents who answered "Yes" and "Between Yes and Neither" favouring the usage of the bus (See Figure 14, central) increased by 7.4 points from No. 1 to No. 3.

The proportion of respondents who answered "Yes" and "Between Yes and Neither" for preferring attachment to the city (1) (See Figure 14, second from left) increased by 4.5 points from No. 1 to No. 3 .

The proportion of respondents who answered "Yes" for preferring attachment to the city (2) (see Figure 14, far left) increased by $16.6 \%$ from No. 1 to No. 3.

The proportion of respondents who answered "very much" and "somewhat", also increased by 11.9 points.

The reason for the large increase was discussed in a special feature in No. 3, which presented the concept of profitability of the bus, the public burden, and the increase in the number of buses.

This article might have given readers an opportunity to think about the continuation of the bus, which was reflected in the results of the questionnaire "There is something sad when it disappears".

In addition, as a side effect of the distribution of LITNs, the number of complaint calls to the city office decreased from "one every three days (monthly average: 8 )" before the distribution, to "less than one per month (monthly average: 0.75: 8 months from November 2019)" after the distribution.

The following is a selection of the responses from the free comment sections of the two questionnaires (see Table 5). Many respondents shared the comment, "I can take the bus more easily and have more opportunities to go out." In addition, many respondents shared that "I no longer have to worry about it", "I can take the bus without hesitation", "I now take the bus", and "I can easily take the bus". Those who purchased the new pass felt more freedom of movement than before, and their lifestyles had changed in some way. 
Table 5. Sampling of opinions.

\begin{tabular}{ll}
\hline \multicolumn{1}{c}{ From } & \multicolumn{1}{c}{ Sampling of Opinions } \\
\hline \multirow{3}{*}{$\begin{array}{c}\text { Readers of lifestyle } \\
\text { information tabloid } \\
\text { newsletters }\end{array}$} & $\begin{array}{l}\text { I was impressed by the tasteful design and readability of the tabloid. Reading the tabloid changed my } \\
\text { image of Oyama city. I was impressed by its tasteful design and readability. }\end{array}$ \\
\cline { 2 - 3 } & $\begin{array}{l}\text { I was impressed by the tasteful design and readability of the tabloid. It is very helpful. } \\
\text { I used to think that buses were for grandparents, but after reading the tabloid, my image has changed. I } \\
\text { would like to ride the bus. }\end{array}$ \\
\cline { 2 - 3 } New pass holders & $\begin{array}{l}\text { The tabloid is full of fresh information and is easy to read, so I decided to visit the places mentioned in } \\
\text { the article. }\end{array}$ \\
\cline { 2 - 3 } & $\begin{array}{l}\text { Commuting and going out in the city has become much easier.I am glad that I can take any bus line. } \\
\text { When I meet a bus, I can take it without hesitation even for a short distance. }\end{array}$ \\
\hline $\begin{array}{l}\text { I am a high school student. Thanks to the new pass, I can take the bus easily even when I don't have } \\
\text { money. I can take the bus not only to school but also to many other places. }\end{array}$ & $\begin{array}{l}\text { I'm talking with some members of the senior citizen's association about buying the new pass and going } \\
\text { on a mini hike. }\end{array}$ \\
\hline
\end{tabular}

\section{Discussion}

Is it possible to reduce bus fares without reducing operational revenues? In a city dependent on private cars, will lowering bus fares encourage bus usage? This is an important issue concerning public transport policies. This study analysed the Oyama city bus social experiment offering a significant fare reduction with a public information campaign for all citizens. The results obtained were as follows:

The price of the bus pass was reduced by Max 70\%, which resulted in a 2.6-fold increase in the number of bus pass holders, a 1.1-fold increase in the total number of annual bus users, and maintenance of bus operational revenues (1.002-fold).

In FY2020, when the full impact of COVID-19 was experienced, both revenue and bus users declined, but at roughly the same percentage. If the fare reduction caused a reduction in revenue, the percentage of decrease in revenue would have been higher. In addition, the percentage decrease in the number of bus users was approximately $5 \%$ lower than that in the surrounding cities.

These results suggest that it might be possible to achieve a significant fare reduction in bus fares without reducing operational revenues (and without needing additional public funding), although this was only a six-month and short-term evaluation. It is also worth noting that the number of new pass holders continues to increase, even today, despite the COVID-19 disaster.

In addition, the significant fare reduction in buses has attracted a different group of bus users, namely workers (62.2\% of all new pass holders) and private car owners (43\% of all new pass holders). The number of times the new pass holders used the bus has increased by 1.16. In particular, the number of bus trips made by new pass holders, who previously used the bus less frequently, increased by a factor of 2.68 .

From a psychological point of view, there has been an increase in the awareness of the new pass, an increase in the number of citizens who favoured the bus and were attached to the city, and a decrease in the number of complaints about the bus to the city hall by a factor of 10. The psychological impact of LITNs is evident. These results suggest that the low-cost method of public information campaigning might have worked as an individual and interactive communication measure with citizens.

Existing studies have shown that TFPs in residential areas of Japan reduced car use by $7.3 \%$ to $19.1 \%$ and increased public transport use by $30.0 \%$ to $68.9 \%$ on average [18].

The low-cost public information campaign targeted all citizens, and the city-wide effect was a 10\% increase (FY2019) in the total number of bus users per year and a $5 \%$ reduction (FY2020) in the rate of decrease in the number of bus users. 
As the public information campaign was carried out at the same time as the fare reduction, the above effect was not the result of the campaign alone. Taking this into account, it was clear that the effect of the low-cost public information campaign method was inferior to that of TFPs. Therefore, it could be argued that if a high effect of promoting public transport usage was desired, time-consuming and costly TFPs should be implemented.

Some proposals for further research are given below. As discussed in previous studies [30], the concept of "breaking the habit" of car use is important when trying to permanently change the modal split and attract more people to public transport. Unfortunately, this study did not investigate the habitual use of cars, as it only surveyed whether people own their own cars. A survey of people in European countries reported that among those who use private cars, about $56 \%$ are ready to change their travel behaviour (travel habits) using other modes of transportation [30]. Since $54.4 \%$ of the new pass holders had their own cars, it can be assumed that the low-cost policy has contributed to breaking the habit of car use to some extent. However, there are about 14.2 ten thousand cars in Oyama City. Therefore, further research is needed to determine whether the low-cost policy measures implemented can affect the habit of car use, and if so, to what extent, and what improvements can be made.

In addition, efforts are underway across the policy measures to change the transport environment and psychological aspects mentioned in this study. In recent years, through the development of applications and the use of information and communication technologies, there have been initiatives (such as Mobility as a Service) that can be called innovations in public transport, such as flexible fare setting and information provision. Such innovative ideas in the field of public transport have been collected using participatory techniques and have analysed how public transportation users hierarchize innovations for public transport [31]. Some of the innovation initiatives in public transport can be implemented at very low cost and may be used for the evolution of new passes to further increase the number of public transport users. If we are to evolve new passes (e.g., to change the price or to offer a combined bus and other transport services, etc.) we need to find user groups, market share and determine the optimal price and other service levels. For this purpose, further research is needed, and conjoint analysis may be an option. We would like to continue our efforts to make the transport environment in Oyama City more appropriate by carrying out further surveys and studies mentioned above.

Finally, the following points would provide public transport practitioners with an insight into the factors that have enabled the achievement of a significant fare reduction on buses, without reducing operational revenues.

- $\quad$ Make public transport fares comparable with other modes of transport.

- This area must have a low level of public transport usage. A low level is assumed to be less than 1\%, as in Oyama City. In areas with high levels of public transport usage, there might be a lack of new users and a lack of capacity for public transport.

- Appropriate public information campaigns would have to be adopted to promote usage.

- Evaluate measures ex ante and ex post, using data on the number of users, income, questionnaires, etc.

The factors that made the public information campaign low-cost method work as an individual and interactive communication measure with citizens are:

- The use of the "lifestyle information tabloid newsletter (LITN)" media for a public information campaign (MM) targeting all citizens. In a public information campaign targeting many people, this media added individuality and interactivity to the information and might be a viable communication measure.

- The basic technology of MM (information provision method, action plan method, TFP, etc.) should be used in the design of the tabloid.

- Emphasis on the importance of branding and design in the production of LITNs and involvement of creative directors and designers in the project. 
This study is concluded with the anticipation that it will assist practitioners involved in public transport.

Author Contributions: Conceptualization, T.A. and A.T.; methodology, T.A. and A.T.; validation, T.A.; formal analysis, T.A.; investigation, T.A., K.N., and A.T.; resources, T.A.; data curation, T.A.; writing—original draft preparation, T.A. and K.N.; writing—review and editing, T.A. and K.N.; visualization, T.A.; supervision, T.A. and A.T.; project administration, T.A. All authors have read and agreed to the published version of the manuscript.

Funding: This research received no external funding.

Informed Consent Statement: This study is an evaluation of the policies implemented by the municipality and is not an experiment on human subjects. Note that the questionnaire for this study was answered by those who agreed to use the data for policy consideration and research which aggregated in a way that prevents the identification of individuals.

Data Availability Statement: The data used in this study was available with permission from Oyama City authorities (Oyama City, https:/ / www.city.oyama.tochigi.jp/site/o-bus/200518.html; accessed on 21 April 2021).

Acknowledgments: In creating the lifestyle information tabloid newsletters, authors received assistance from the creative director Katagiri, A. and designer Saito, A. Bus data was provided by Uehara, Y. and Uchida, N. of Oyama City authorities.

Conflicts of Interest: The authors declare no conflict of interest.

\section{References}

1. Ministry of Land, Infrastructure, Transport and Tourism in Japan. The current state of regional transport. In The White Paper on Land, Infrastructure, Transport and Tourism in Japan; Japan; 2020; pp. 33-34. Available online: https:/ / www.mlit.go.jp/hakusyo/ $\mathrm{mlit} / \mathrm{r01} /$ hakusho/r02/pdf/English\%20Summary.pdf (accessed on 21 April 2021). (In Japanese)

2. Urban Transport Planning Office, City Planning Division, Urban and Regional Development Bureau, Ministry of Land, Infrastructure, Transport and Tourism in Japan. LRT ingenuity in other countries. In Guidance on LRT Introduction Plan Integrated with Urban Development, Transport and Tourism in Japan; Japan; 2005; pp. 18-28. Available online: https:/ /www.mlit.go.jp/english/ white-paper/mlit05.html (accessed on 21 April 2021). (In Japanese)

3. Ministry of Land, Infrastructure, Transport and Tourism in Japan. Use of fee policies overseas. In The White Paper on Land, Infrastructure, Transport and Tourism in Japan; Japan; 2013; pp. 48-50. Available online: https://www.mlit.go.jp/en/statistics/ white-paper-mlit-2013.html (accessed on 21 April 2021). (In Japanese)

4. Hay, A. The Impact of Subsidised Low-Fare Public Transport on Travel Behaviour. Environment and Planning C. Gov. Policy 1986, 4, 233-246. [CrossRef]

5. Tsukamoto, N.; PERRY, F. An Analysis on the Effects to Tram Demand by Official Financing Package Based on the Hankai Tramway Case. J. Hum. Environ. Osaka Sangyo Univ. 2017, 16, 65-78. (In Japanese)

6. Fujii, S.; Kitamura, R. What does a one-month free bus ticket do to habitual drivers? An experimental analysis of habit and attitude change. Transportation 2003, 30, 81-95. [CrossRef]

7. Kamada, Y.; Matsunaka, R.; Oba, T.; Nakagawa, D.; Suzuki, Y.; Honda, S. Impact analysis of reduced fare programme for older people on step counts per day and travel behaviour. Int. J. Transp. Dev. Integr. 2018, 2, 155-165. [CrossRef]

8. Fujii, S.; Taniguchi, A. Determinants of the effectiveness of travel feedback programs-a review of communicative mobility management measures for changing travel behaviour in Japan. Transp. Policy 2006, 13, 339-348. [CrossRef]

9. Taniguchi, A.; Fujii, S. Promoting public transport using marketing techniques in mobility management and verifying their quantitative effects. Transportation 2007, 34, 37-49. [CrossRef]

10. Enoch, M. Sustainable Transport, Mobility Management and Travel Plans; Routledge: Abingdon, UK, 2016; ISBN 9781315611563.

11. Taylor, M.A.P. Voluntary travel behavior change programs in Australia: The carrot rather than the stick in travel demand management. Int. J. Sustain. Transp. 2007, 1, 173-192. [CrossRef]

12. Bamberga, S.; Fujii, S.; Friman, M.; Gärling, T. Behaviour theory and soft transport policy measures. Transp. Policy 2011, 18, 228-235. [CrossRef]

13. Nurdden, A.; Rahmat, R.A.O.K.; Ismail, A. Effect of Transportation Policies on Modal Shift from Private Car to Public Transport in Malaysia. J. Appl. Sci. 2007, 7, 1013-1018. [CrossRef]

14. Anwar, A.M.; Yang, J. Examining the Effects of Transport Policy on Modal Shift from Private Car to Public Bus. Procedia Eng. 2017, 180, 1413-1422. [CrossRef]

15. Tuan, V.A. Mode Choice Behavior and Modal Shift to Public Transport in Developing Countries-The Case of Hanoi City. J. East. Asia Soc. Transp. Stud. 2015, 11, 473-487. 
16. Sunio, V.; Schmöcker, J.; Estuar, R.; Dela, B.L. Development and Usability Evaluation of Blaze Information System for Promoting Sustainable Travel Behaviour in Metro Manila. J. East. Asia Soc. Transp. Stud. 2017, 12, 2428-2443.

17. Sunio, V.; Schmöcker, J.D. Can we promote sustainable travel behavior through mobile apps? Evaluation and review of evidence. Int. J. Sustain. Transp. 2017, 11, 553-566. [CrossRef]

18. Taniguchi, A.; Suzuki, H.; Fujii, S. Mobility Management in Japan: Its Development and Meta-Analysis of Travel Feedback Programs. Transp. Res. Rec. 2007, 2021, 100-117. [CrossRef]

19. Sasaki, H.; Fujimoto, S.; Taniguchi, A.; Nakahara, S. Mobility Management for Health Promotion in Cooperation with Local Government Urban Transport Planning and Public Health Departments. J. Transp. Health 2017, 5, S90. [CrossRef]

20. Urban Transport Planning Office, City Planning Division, Urban and Regional Development Bureau, Ministry of Land, Infrastructure, Transport and Tourism in Japan. Construction cost of LRT. In Guidance on LRT Introduction Plan Integrated with Urban Development, Transport and Tourism in Japan; Japan; 2005; p. 36. Available online: https://www.mlit.go.jp/index_e.html (accessed on 21 April 2021). (In Japanese)

21. Minami, S. Implication from History of "Versement Transport"-French urban transport tax. Public Financ. Public Policy 2012, 34, 122-137. (In Japanese)

22. Minami, S. Considerations on Rights to Transport of Elderly People and Intergenerational Equity in French Urban Transportation Tax. J. Jpn. Sci. 2013, 48, 24-29. (In Japanese)

23. Brown, J.; Hess, B.D.; Shoup, D. Fare-Free Public Transit at Universities: An Evaluation. J. Plan. Educ. Res. 2003, $23,69-82$. [CrossRef]

24. Brown, J.; Hess, B.D.; Shoup, D. Unlimited Access. Transportation 2001, 28, 233-267. [CrossRef]

25. Taniguchi, A.; Fujii, S. Mobility management in Australia: Practices in Perth and Adelaide and Comparison between them. Infrastruct. Plan. Rev. 2008, 25, 843-852, (In Japanese with English abstract). [CrossRef]

26. Miyakawa, A.; Shimada, K.; Sakai, H.; Fujii, S. A study on the effect of mobility management using mass-media. Proc. Res. Meet. Civ. Eng. Plan. 2008, 37, 18, (In Japanese with English abstract).

27. Fearnley, N. Free Fares Policies: Impact on Public Transport Mode Share and Other Transport Policy Goals. Int. J. Transp. 2013, 1, 75-90. [CrossRef]

28. Transport in Tochigi (FY2018 Version). Available online: https://www.pref.tochigi.lg.jp/h03/town/koukyoukoutsuu/ koukyoukoutsuu/documents/tochigi_kokyokotsu_2018.pdf (accessed on 21 April 2021). (In Japanese).

29. Fujii, S.; Taniguchi, A. Reducing family car use by providing travel advice or requesting behavioural plans: An experimental analysis of travel feedback programs. Transp. Res. D 2005, 10, 385-393. [CrossRef]

30. Tsafarakis, S.; Gkorezis, P.; Nalmpantis, D.; Genitsaris, E.; Andronikidis, A.; Altsitsiadis, E. Investigating the preferences of individuals on public transport innovations using the Maximum Difference Scaling method. Eur. Transp. Res. Rev. 2019, 11, 3. [CrossRef]

31. Nalmpantis, D.; Roukouni, A.; Genitsaris, E.; Stamelou, A.; Naniopoulos, A. Evaluation of innovative ideas for Public Transport proposed by citizens using Multi-Criteria Decision Analysis (MCDA). Eur. Transp. Res. Rev. 2019, 11, 22. [CrossRef] 